CONF-950956--8 GA-A22172

\title{
RF POWER DIAGNOSTICS AND CONTROL ON THE DIII-D, 4 MW 30-120 MHz FAST WAVE CURRENT DRIVE SYSTEM (FWCD)
}

by

S.W. FERGUSON, R.W. CALLIS, W.P. CARY,

T.E. HARRIS, and J.C. ALLEN

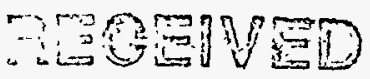

MAR 17 的

OSTI

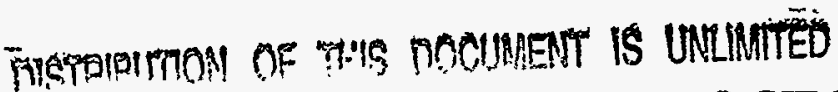

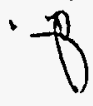

OCTOBER 1995

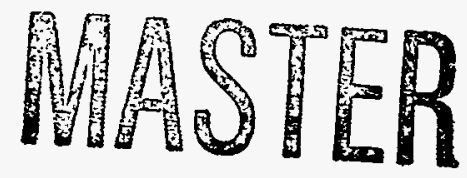




\section{DISCLAIMER}

This report was prepared as an account of work sponsored by an agency of the United States Government. Neither the United States Government nor any agency thereof, nor any of their employees, makes any warranty, express or implied, or assumes any legal liability or responsibility for the accuracy, completeness, or usefulness of any information, apparatus, product, or process disclosed, or represents that its use would not infringe privately owned rights. Reference herein to any specific commercial product, process, or service by trade name, trademark, manufacturer, or otherwise, does not necessarily constitute or imply its endorsement, recommendation, or favoring by the United States Government or any agency thereof. The views and opinions of authors expressed herein do not necessarily state or reflect those of the United States Government or any agency thereof. 


\section{DISCLAIMER}

Portions of this document may be illegible in electronic image products. Images are produced from the best available original document. 


\section{RF POWER DIAGNOSTICS AND CONTROL ON THE DIII-D, 4 MW 30-120 MHz FAST WAVE CURRENT DRIVE SYSTEM (FWCD)}

by

S.W. FERGUSON, * R.W. CALLIS, W.P. CARY, T.E. HARRIS, and J.C. ALLEN*

This is a preprint of a paper presented at the 16th IEEE/NPSS Symposium on Fusion Engineering, September 30-October 5, 1995, Champaign, Illinois, and to be printed in the Proceedings.

Work supported by

U.S. Department of Energy Contracts W-7405-ENG-48 and DE-AC03-89ER51114

*Lawrence Livermore National Laboratory

GENERAL ATOMICS PROJECT 3466 OCTOBER 1995 


\title{
RF Power Diagnostics and Control on the DIII-D, 4 MW 30-120 MHz Fast Wave Current Drive System (FWCD) ${ }^{*}$
}

\author{
S.W. Ferguson, ${ }^{a}$ R.W. Callis, ${ }^{b}$ W.P. Cary, ${ }^{\text {b T.E. Harris, }}{ }^{\text {b }}$ and J.C.Allen ${ }^{b}$ \\ a Lawrence Livermore National Laboratory, P.O. Box 808, Livermore, California 94551-9900

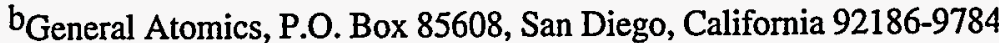

\section{ABSTRACT}

The Fast Wave Current Drive System uses three $2 \mathrm{MW}$ transmitters to drive three antennas inside the DIII-D vacuum vessel. This paper describes the diagnostics for this system.

\section{INTRODUCTION}

General Atomics personnel have developed a diagnostic system for the transmitters that measure the forward and reflected power plus voltages and currents in 56 places in the two transmission lines. Additionally the phase of all of these signals are measured to an accuracy of about $1^{\circ}$ on a real time basis during a DIII-D shot. A unique super-heterodyne receiver topology for the General Atomics diagnostics allows the two transmitters to operate at full power and within $1 \mathrm{MHz}$ of each other without interference or diagnostic signal contamination. All power and voltage measurements that are critical to the transmitter or transmission line protection are made on a microsecond time scale. Other measurements, made on a microsecond time scale. Other measurements, such as phase, that are only used for plasma diagnostics or system retuning are made on a $100 \mu$ s time scale. Another unique feature of the super-heterodyne receiver is the ability to make accurate (phase locked) measurement of the power and phase throughout the system while the transmitters are being frequency modulated to track transient plasma phenomenon. Because of the power and phase diagnostics throughout the system the transmitters can be exactly tuned to match the plasma with only one tuning shot into the plasma. This facilitates maximum rf power utilization.

\section{RF DIAGNOSTICS}

Fig. 1 shows the block diagram for one of the two the DIII-D Fast Wave Current Drive Systems. The transmitter drives a $3 \mathrm{db}$ hybrid power splitter which divides the transmitter power equally into two paths. Each of the two lines is matched to 50 ohms by a phase shifter and stub matching network. Additionally one path has a $360^{\circ}$ phase shifter capable of shifting the phase in one of the lines an arbitrary

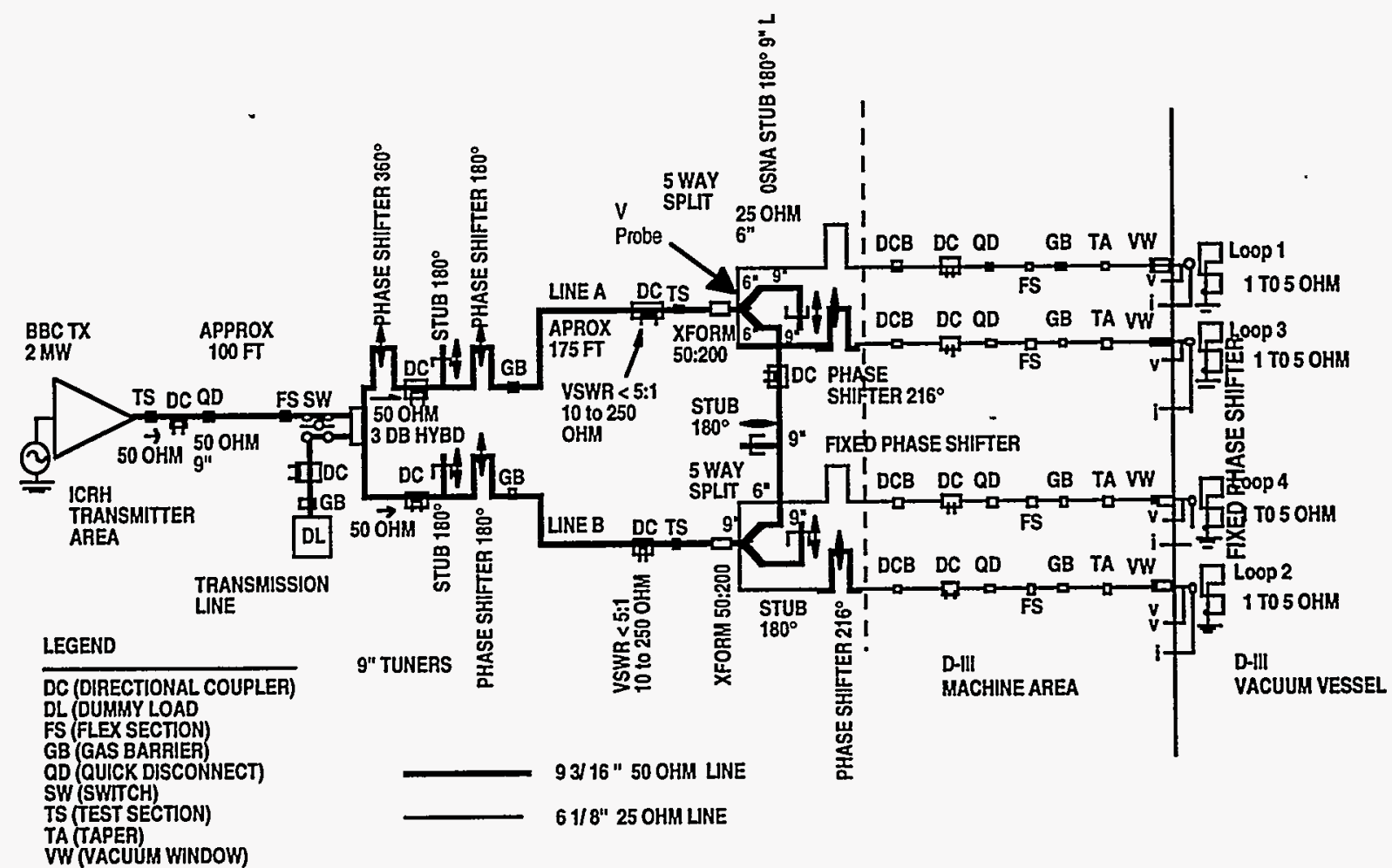

Fig. 1. DIII-D transmission line and antenna tuners

\footnotetext{
*Work supported by the U.S. Department of Energy under Contract Nos. W-7405-ENG-48 and DE-AC03-89ER51114.
} 
amount relative to the other line. The power from each of the two $50 \mathrm{ohm}$ lines is split into two additional paths at a resonant five-way tee junction. The two outputs of the tee junction are then used to drive the individual straps of a fourstrap fast wave current drive antenna inside the vacuum vessel. The five-way tee junctions are coupled through a stub tuner that allows the operator to compensate for unequal coupling between the straps of the antenna.

The diagnostics for this system consist of nine directional couplers, six voltage probes and four current probes. All of these diagnostics are amplitude and phase detected. The detected signals are digitized and transferred to the DIII-D data archive system between shots. Additionally selected signals are transmitted to the operator via analog fiber optic links. These signals are displayed on oscilloscopes on the operator console and are used to give the operator real time feedback on the shot status.

Fig. 2 is a block diagram of the typical diagnostic configuration used to provide amplitude and phase detection for the fast wave current drive system. The block diagram of Fig. 2 shows the heterodyne frequency configuration that is used to generate the transmitter drive signal, the rf detector local oscillator (LO) signals, and the system calibration signal. Only the signal processing of one typical channel is shown. The local oscillator signals are split to drive the 56 individual amplitude/phase detectors in the system.
The transmitter drive signal, $30-120 \mathrm{MHz}$, is derived from a high stability $10 \mathrm{MHz}$ oven controlled crystal oscillator (OCXO). This oscillator is used as the reference signal for two PTS310 signal generators. Since the PTS310 signal generators produce their output frequency by dividing, multiplying, and heterodyning harmonics and sub-harmonics of the $10 \mathrm{MHz}$ reference signal to generate their output frequency, the output frequency of the two PTS 310 generators are both phased locked to the same reference and thereby to each other. One of the signal generators has a built in $150 \mathrm{MHz}$ output that is generated from the 15th harmonic of the $10 \mathrm{MHz}$ oscillator. The drive signal for the transmitter and the local oscillator for the amplitude/phase detector are both derived by mixing the outputs of one of the PTS310 signal generators with the $150 \mathrm{MHz}, 15$ th harmonic of the $10 \mathrm{MHz}$ frequency standard. The $150 \mathrm{MHz}$ signal is mixed with a PTS310 output signal in the range $180-270 \mathrm{MHz}$ to generate the $30-120 \mathrm{MHz}$ signal to drive the transmitter and with $169.99-259.99 \mathrm{MHz}$ to generate the $19.99-109.99 \mathrm{MHz}$ local oscillator reference. Since both the transmitter drive signal and the LO signal are derived by mixing the $150 \mathrm{MHz}$ with PTS310's, when the $150 \mathrm{MHz}$ is replaced by a $150 \mathrm{MHz}$ VCO the transmitter and LO signals can be frequency modulated simultaneously so that when the signals are detected in the amplitude/phase detector modules the phase detection will still be accurate even while the transmitter is being frequency modulated within it $\pm 150 \mathrm{kHz}$ bandwidth.

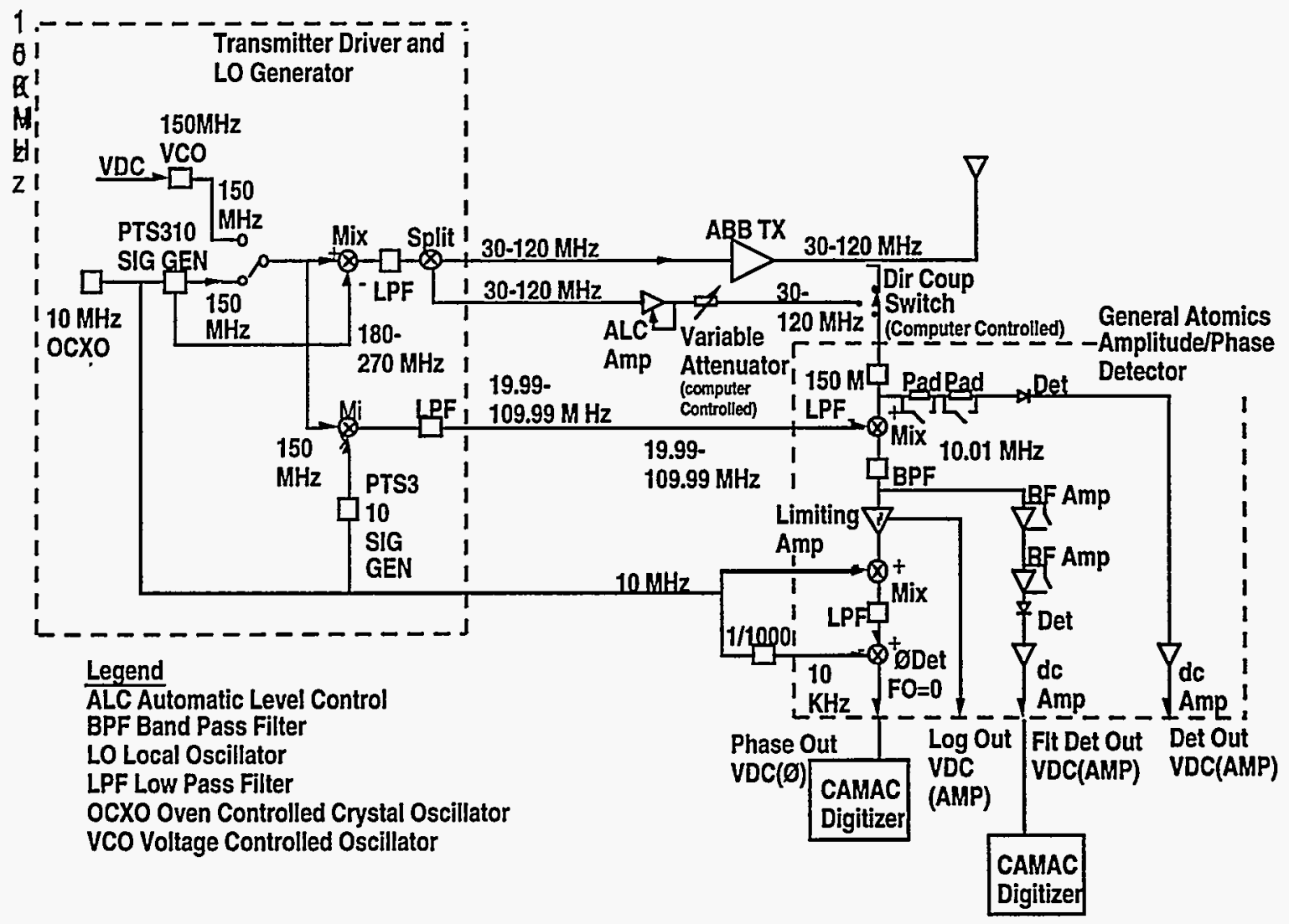

Fig. 2. DIII-D fast wave current drive amplitude and phase detection 
The rf output from the directional coupler is run on $50 \mathrm{ohm}$ coax, RG-58, to the computer controlled if switch (usually within 20 to $50 \mathrm{ft}$ ). The switch is used to either apply the normal directional coupler if signal or a computer controlled calibration signal to the amplitude/phase detectors input. The input to the amplitude/phase detector is low pass filtered and then split between a mixer and a group of computer controlled rf pads. The output of the pads is if detected and then dc amplified to provide a dc signal proportional to rf power.

The other path for the if is mixed with a phase locked LO that translates the if signal to a $10.01 \mathrm{MHz}$ Intermediate frequency (IF). The $10.01 \mathrm{MHz}$ IF is band pass filtered by a four-pole $\mathrm{L}-\mathrm{C}$ filter with a $0.5 \mathrm{MHz}$ bandwidth and a $1100 \mathrm{~ns}$ group delay. Fig. 3(a) and 3(b) shows the typical frequency and group delay characteristics of the filter. The $0.5 \mathrm{MHz}$ bandwidth was chosen as a compromise between rejection of transmitters operating on nearby frequencies and fast response for arc detection and protection of the transmitters. The calibrated $1100 \mathrm{~ns}$ group delay through the filter assures that the amplitude/phase detectors all have the same phase shift through the detection system. Also the switch on the input of each amplitude/phase detector allows the phase indication of each detector to be calibrated daily or as often as the system operator chooses. The long term phase drifts in the system have been small or insignificant. The system has operated for months at a time without phase calibration.

The output of the $10.01 \mathrm{MHz}$ band pass filter is split into two paths. One path goes through a series of switchable, computer controlled, if amplifiers. The output of the rf amplifiers is diode detected and dc amplified to provide a dc level proportional to transmitter power. This signal is

Filter Amplitude vs. Frequency

(a)

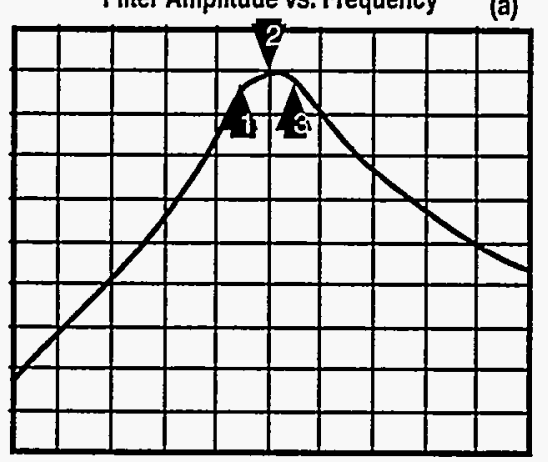

Center $10.010000 \mathrm{MHz}$

Span $5.000000 \mathrm{MHz}$

Group Delay vs. Frequency

(b)

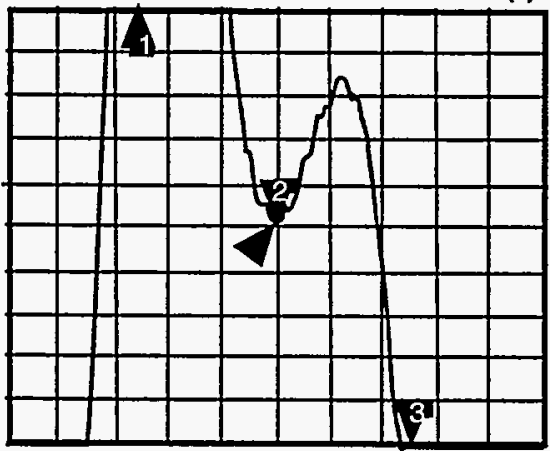

Center $10.010000 \mathrm{MHz}$

Span $2.000000 \mathrm{MHz}$

Fig. 3. IF filter amplitude and group delay. normally used to monitor system performance since it rejects interference from other transmitters. Fig. 4 shows the dc output voltage as a function of if input power for this detector. The signal is digitized locally and transmitted to the DIII-D data archival system via a digital IEEE-488 fiber optic link. The other output of the bandpass filter is used for phase detection. The signal is applied to a $70 \mathrm{~dB}$ dynamic range limiting amplifier which eliminates amplitude variations but preserves phase information. The output of the limiting amplifier is then mixed with the $10.0 \mathrm{MHz}$ master standard oscillator to generate a $10 \mathrm{kHz}$ IF. The $10.0 \mathrm{kHz}$ IF is then phase detected relative to a $10 \mathrm{kHz}$ local standard phase reference derived from the $10.0 \mathrm{MHz}$ master standard oscillator. Fig. 5 shows the phase detector accuracy as a

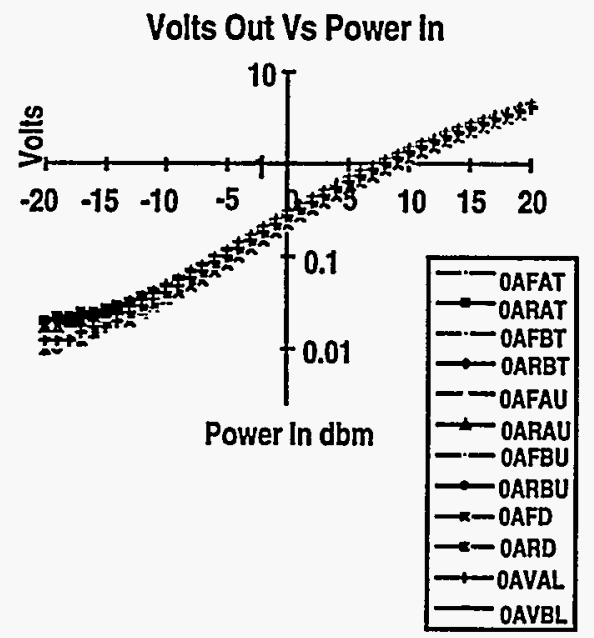

Fig. 4. Amplitude detector voltage out vs. power in.

Phase Vs Power Input
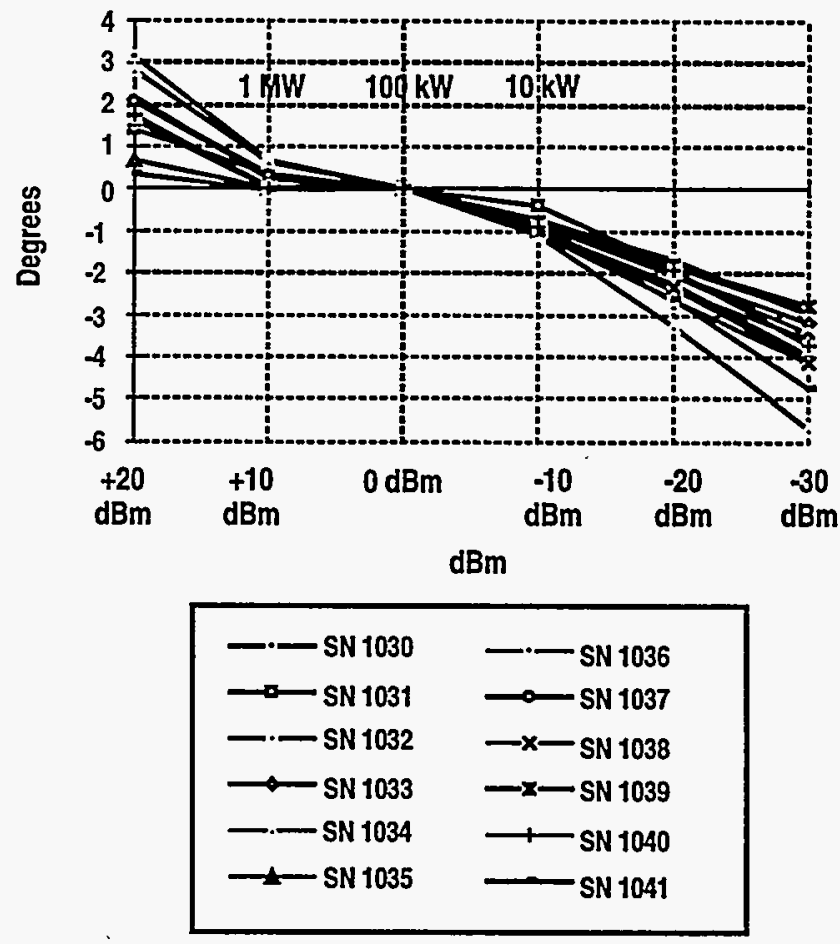

Fig. 5. phase detector accuracy vs input level. 
function of input level for 12 amplitude/phase detectors. The data was taken at $90 \mathrm{MHz}$ at input levels from $+20 \mathrm{dbm}$ to $-30 \mathrm{dBm}$. Phase accuracy over the nominal system operating range of $20 \mathrm{~dB}$ ( $1 \mathrm{MW}$ to $10 \mathrm{~kW})$ is about \pm 1.0 degrees. The output of the phase detector is measured digitally to a precision of \pm 0.3 degrees. The signal can either be recorded digitally with a dual port memory or converted to a analog signal and recorded with a ADC digitizer.

\section{CONCLUSION}

The diagnostics associated with the General Atomics Fast Wave Current Drive System allow the system tuning to be analysed and modified on a between shot basis. The transmitters can be exactly tuned to match the plasma with only one tuning shot into the plasma. This facilitates maximum rf power utilization. 